pound infected fractures of the humerus, even when accompanied by an extensive loss of bone and soft parts, yield much more readily to treatment than do similar injuries to the femur. Whether this is due to a better blood-supply to the upper extremity, or whether the foyer of fracture is easier of access here will not now be discussed, but the fact remains, and will probably become more and more evident during the course of the war. Amputation of the arm has rarely to be resorted to unless there is injury to the brachial artery high up, or unless some complication, such as gas gangrene, sets in. Amputation through the thigh, however, must be done in a fairly large proportion of cases, as it must be borne in mind that these patients become rapidly septic so that the first indication is to save the patient's life, the second to save the limb and the third to preserve as much function as possible. Conservatism in the treatment of these fractures is the rule in France and England. I have it on very good authority that such is not the case in the German army.

Conservatism is, of course, to be encouraged, but the treatment of these fractures is one that requires absolutely the best of surgical judgment. Good and efficient drainage must be established early and be. maintained. Loose fragments of bone or pieces of shrapnel must be removed. The postoperative treat ment is more important than the operation. The limb must be immobilized, and in the case of the femur, extension must be employed. A plaster hip spica, although carrying out both immobilization and extension, has been found to be impracticable. It soon becomes loose as the swelling of the limb decreases, and is dirtied in a very short time, as the amount of discharge from these wounds is enormous. The simplest method and the most practicable consists in extension with weights and immobilization by means of wooden splints on a fracture pillow. An idea of the gravity of these fractures, and the difficulties in their treatment, may be somewhat appreciated when it is remembered that these patients have for several months been living under a terrible strain, and often with insufficient food. The reason that conservatism can be used at all is that all these patients are young men.

Of the two dreaded complications of gunshot injuries - tetanus and gas gangrene - it is much too early in the war to speak. The French government had a supply of antitetanic serum on hand, so that it was a rule in many base hospitals that every soldier should be given an immunizing dose on admission. An idea of the comparative rarity of tetanus can be gathered when it is stated that in four hospitals in Paris - each with a capacity of about 400 beds - not one has had more than six cases.

Gas gangrene, however, is much more common and is especially prone to follow shrapnel wounds of the thigh. The methods of treatment differ in various hospitals. Most of the French surgeons do not believe in extremely large incisions for drainage, but make comparatively small ones, which are frequently irrigated with peroxid. Many are in favor of draining and forcing oxygen gas under pressure into the affected tissues for a considerable length of time from twelve to seventy hours. This can be repeated at intervals if the process does not resolve. Both these methods of treatment have given good results in some cases, but in many others amputation has to be done, and very often this is of little avail.

For the privilege of having been able to operate in and treat a number of the cases mentioned here $I$ wish to thank Dr. Du Bouchet, Surgeon-in-Chief of the American Ambulance at Neuilly. To the many other surgeons in Paris, by whose courtesy I was able to see the cases under their care, my thanks are also due. The roentgenograms reproduced here were kindly made for me by Dr. Jaugeas and Mr. King of the roentgenographic department of the American Ambulance at Neuilly.

40 East Forty-First Street.

\section{THE RELATION OF POSTURE AND INTESTINAL DERANGEMENTS TO COXITIS*}

\section{ROBERT B. OSGOOD, M.D. BOSTON}

The title of this communication is misleading. One has a right to infer that I shall at least attempt to explain the relation of posture and intestinal derangements to coxitis. I shall offer no explanation, however, and there should be an interrogation mark after the last word.

The paper is simply a report and a consideration of three cases in which there was an apparent relationship between faulty posture or intestinal derangements and coxitis, and in which the discovery of this relation made unnecessary any prolonged local treatment of the coxitis. The excuse for its presentation is the hope that not all of those present have noted such an association. If this is so and your experience should tally with mine it is possible that you may occasionally be spared a modicum of anxiety, a few families may be spared the distress which the diagnosis of tuberculosis always brings, and certain patients may be spared a prolonged and irksome treatment which may not be demanded.

You are all familiar with the belief held by Sir Arbuthnot Lane ${ }^{1}$ that unless the capacity of the several tissues of the body to resist the entry of certain organisms is inhibited by an auto-intoxication resulting from intestinal stasis, it is impossible for these diseases to develop. Therefore, to meet these diseases he adopts measures to improve the drainage scheme and cites cases in which rapid disappearance of large masses of tuberculous glands in the abdomen has occurred, following disconnection of the large bowel.

Fraser, ${ }^{2}$ writing on the types of organism in bone and joint tuberculosis in children, is quite convinced that the more common bovine form enters usually by the mouth in milk. It is probably true that an intestinal stasis favors extension to the bones and joints.

Barrington-Ward, ${ }^{3}$ working at Great Ormond Street, reports a case of double tuberculous disease of the hip with sinuses, in which orthopedic treatment had been unavailing, but in which rapid recovery followed a short circuiting operation after the manner of $\mathrm{Mr}$. Lane.

It is not, however, to suggest that faulty posture and intestinal derangements bear a causative relation

* Read before the Section on Orthopedic Surgery at the Sixty-Fifth Annual Session of the American Medical Association, Atlantic City, N. J., June, 1914.

1. Lane, Arbuthnot: Lancet, London, Dec. 14, 1912

2. Fraser, S.: Brit. Med. Jour., April 12, 1913.

3. Barrington-Ward, L. E.: Surg., Gynec. and Obst., July, 1912. 
to tuberculous coxitis that these cases are reported. I should be disinclined to deny the possibility of such a relationship, but in this paper I wish rather to suggest that associated with certain intestinal derangements and faulty posture in children there may exist a toxemic arthritis indistinguishable clinically from tuberculosis of the hip.

Thanks to the work of careful pathologists, among whom your Chairman and honored guest are eminent, we know many of the changes which take place in tuberculous disease of the joints. These changes are fairly constant. Tubercles are present, the synovial membrane proliferates, erosion of cartilage appears, and bone foci follow or antedate the involvement of the synovia.

Poncet $^{4}$ and others have described a rhumatisme tuberculeuse due to toxins elaborated in, and disseminated from, a tuberculous focus in some other part of tion is strong evidence that no active tuberculous process of any sort is present.

\section{REPORT OF CASES}

CASE 1.-History.-Girl, aged 6 years, 3 months. Oldest child of a physician, carefully brought up under absolutely hygienic surroundings outside the city. She was first seen six months ago with symptoms in the right hip which had been intermittently present for four months. The family bistory was good. The past history showed digestive troubles dating back to her first year, continued into her second year, and followed by a more or less chronic constipation and occasional "upsets." During the last four months there had been repeated complaints of pain in the right thigh and the right knee, but never any lasting limp. Three days before being seen she had walked two miles and came back tired, with complaint of pain in the thigh near the knee. Her present illness began on the day on which she was seen. She had started to get up at 5 a. $\mathrm{m}$. to urinate and found it was painful to bear weight on her right leg. There had been no night cries or night sweats. There was little pain at rest or on slight passive movement.

Examination. - The general examination by a careful internist had been negative. The child was poorly nourished, with little color. She stood favoring the right leg, with a prominent abdomen, flat chest, hollow back, forward shoulders, prominent scapulae, pronated feet, and an attitude suggestive of congenital visceral ptosis. The length of the legs was the same. The circumference of the calves and thighs was the same on each side. The motions of the spine and all other joints except the right hip were free and painless. The motions of the right hip were limited, painful and accompanied by spasm in extremes of flexion, rotation and hyperextension. Jarring was only slightly painful. Palpation was negative except for some tenderness to deep pressure over the head of the bone. A definite diagnosis was with-
held.

Fig. 2.-Corrected standing position with posFig, $2 .-$ Corrected
tural brace, Case 2 . the body. If such a condition obtains it is probable that joints thus affected may completely recover if the focus can be eradicated.

On the other hand, although my experience has not been large, I believe that I have never seen a joint recover complete range of motion or perfect function in which the clinical signs over a considerable period of time were typical of tuberculosis and in which the clinical diagnosis was confirmed by tuberculin reactions, roentgenoscopy or exploratory operation and pathologic examination. I recognize that this experience is at variance with many reported complete cures of tuberculous disease, especially of the hip-joint. My conviction, however, is strengthened by the cases to be reported, which presented quite typical clinical pictures of tuberculosis. All of these to-day have perfect hip-joint motion and perfect function. In all three a carefully done von Pirquet test was absolutely negative, and I am led to believe that a negative reac-

4. Poncet: Presse Méd., March 26, 1913.
Treatment and Subsequent History--Recumbency in the open air was advised, in positions to stretch out the flat chest and tighten the lax abdominal wall. The child was to assume twice a day for five or ten minutes an inverted position with thighs on the low bed and head on a pillow on the floor; mechanical cathartics, liquid petrolatum and agar-agar were ordered, and she was measured for a back brace with abdominal pad to correct the standing position, support the abdomen and maintain proper posture. The pronation of the feet was corrected. For one week the symptoms remained about the same with some diminution of pain and sensitiveness. There developed $0.5 \mathrm{~cm}$. atrophy of right calf. Excellent roentgenograms of the two hips on the same plate and of the two hips singly were negative as to bone disease. The von Pirquet test made a little later was absolutely negative. The child was gotten up with the brace, but without protection to the hip-joint, and exercises to improve her posture and abdominal and back musculature were prescribed under careful supervision.

There was rapid improvement in nutrition and color, together with a complete disappearance of objective and subjective symptoms in the right hip-joint. An appearance of health not before present gradually ensued and was note- 
worthy. Four months later the patient, after some error of diet, had a severe urticaria and went for several days without her brace or exercises or the assumption of the corrective positions. Within a few days there was an acute digestive upset, but without symptoms in the hip except perhaps a slight guarding.

At present she is active, faithful to exercises and positions, wearing the brace half the day, and without subjective symptoms. The right hip has normal motion in all directions. The thighs and calves measure the same on the two sides. The right leg is now nearly a centimeter longer than the left, presumably from the stimulation of epiphyseal growth caused by the toxemic arthritis.

CASE 2.-History.-Patient of Dr. F. W. Taylor of Cambridge, boy, aged 4 years, 5 months. Oldest child of a man of leisure, carefully brought up under hygienic surroundings in the outskirts of a city. He was first seen five months ago for symptoms in the right hip which had been intermittently present for one year. The family history is negative except that the mother may be described as delicate. The past history showed mild digestive troubles, perhaps not more than in many children, but for over a year the occasional association of pain in the knee with these upsets. This pain usually occurred at night and amounted to typical night cries. There had been no limping in the morning which followed these first attacks of night pain. In the spring of 1913 he had two attacks of bronchitis and croup, and has seemed less well ever since. During the summer, six months before being seen, there had been a very acute digestive upset amounting to almost complete obstruction. Since this time there has been a tendency to constipation. One month before being seen the child had had a slight fall in his play, had limped for a day or two, and complained of pain for a day or two longer. There were occasional night cries as before. Three weeks before being seen he began to limp and to complain of pain in his right leg and knee. The next day he could scarcely walk, but on the day following he was better, and the symptoms gradually passed off. Soon after that he had another attack of croup, and an adenoid operation was advised by an able laryngologist. One week before being seen he had such an acute attack of pain in his right leg that the child screamed when touched and the family physician noticed that the hip-joint motions were greatly limited. The adenoid operation was performed five days before he was seen, and the hip had very rapidly improved while he was recumbent and after the catharsis previous to the operation.

Examination.-The general.examination by a careful internist, except for the adenoids and enlarged tonsils, had been negative. The child was rather poorly nourished and of poor color, doubtless accentuated by the recent operation. $\mathrm{He}$ stood evenly on both legs, with prominent abdomen, narrow, flattened chest, forward shoulders, prominent scapulae, and an attitude suggestive of congenital visceral ptosis (Fig. 1). The length of the legs was the same. The circumferences of the calves and thighs were equal on both sides. The motions of the spine and all other joints, except the right hip, were free and painless. The motions of the right hip were nearly normal, but on careful examination there was distinct restriction and slight spasm in hyperextension and rotation. No sensitiveness to jarring. Palpation was negative.
Treatment and Subsequent History.-The child was not put to bed, but the positions described in Case 1 were shown. Mechanical cathartics were advised and he was measured for a back brace with an abdominal pad to correct the standing position, support the abdomen and maintain the proper posture (Figs. 2, 3 and 4). A moderate amount of weightbearing was allowed. A provisional diagnosis of toxemic arthritis was made. Roentgenograms taken of both hips on the same plate and of each hip singly were negative. The von Pirquet test was absolutely negative. All the subjective symptoms disappeared, and although the boy had subsequently a second adenoid operation and a tonsillectomy, there was no recurrence of leg pain until about seven weeks ago, when he complained of slight pain in the knee for a few hours, May 2 and 3. He was seen, May 4, but the examination showed normal conditions except for the faintest suggestion of limitation in hyperextension. The boy is now apparently entirely well, with good color, and has had no digestive upsets or sluggishness of the bowels.

CASE 3.-History.-Girl, aged $141 / 2$ months. Only child of people in good circumstances, living in New York City, and referred by a prominent and careful orthopedic surgeon. She was first seen about three months ago and the symptoms had been present for three months. The family history was negative. She had been a bottle-fed baby, great difficulty having been experienced in her early feeding. A proprietary food seeming to agree best, she had been fed on this. After a digestive upset with vomiting, the mother noticed that although she had begun to bear weight and to stamp her feet, she ceased doing so on her right leg, and weight-bearing was painful. When the right leg was raised or moved roughly the child cried. There were typical night cries as well. The family physician was summoned and the orthopedic consultant referred to above was advised by him. The general examination was said to be negative, changes in the diet were suggested in the line of more natural food, orange juice, etc., recumbency and traction were ordered, and a provisional diagnosis of tuberculosis of the right hip-joint made. Within a short time the pain and spasm and night cries having disappeared a short plaster spica was applied by the family physician. This first plaster was worn until three weeks before the child was seen by me, and then a new cast was applied. The family soon moved to the neighborhood 
of Boston, and the second cast being foul with urine, etc., was removed by a local physician the day before the child was brought to me. During the one night on which she slept without the cast there was no night cry. Since the cast had been applied the digestive upsets had ceased, but the stools had often been hard.

Examination.-The general examination was negative. The baby was well nourished, healthy looking, moving both legs with apparent equal freedom and power. There was no evidence of any sensitiveness or guarding in any of the voluntary movements of the right leg. There were no signs of rickets or scorbutus. The abdomen was prominent, but not tender. As far as could be determined, the legs were the same length. The circumference of the calves of both legs were equal, the right thigh a centimeter smaller in circumference than the left, $8 \mathrm{~cm}$. above the upper border of the patella. The motions of all the joints, including the spine and right hip, were free and painless. Palpation was negative. There was no pain on jarring. During the office visit the child had a movement of the bowels consisting of a hard scybalous mass quite different from the normal movements at this age. Roentgen examination was negative except for a slight thinning of the cortex on the right. The child moved slightly and the examination was not entirely satisfactory.

The final diagnosis was withheld until a von Pirquet reaction could be done, but the possibility of the condition being other than tuberculosis was discussed with the mother.

Treatment and Subscquent IIistory.-The child was placed in recumbency, the bowels were regulated with liquid petrolatum. and the case was referred to a pediatrician for careful examination, regulation of the diet. and a von Pirquct test. No fixation or traction to the right hip was advised. The local physician was asked to make daily visits with his observation directed toward any suggestion of a recurrence of symptoms. The von Pirquet test was absolutely negative. The child was seen again one week later. There had been no noticeable subjective symptoms, although on two or three occasions the child had wakened at night and cried, but not typically as before. The right leg at rest secms to be held in a slightly abducted position. There is no suggestion of limitation of motion in any direction nor any pain on manipulation or jarring. The chili has remained well up to the last report.

\section{SUMMARY}

No definite conciusions can be drawn from so small a number of cases. They seem to me to indicate the importance of (1) a careful history, (2) a search for possible causes of toxemia, (3) a von Pirquet test and perhaps tuberculin tests with Koch's old tuberculin for the local reaction if the skin test is positive, (4) a provisional diagnosis at the first visit, and (5) the withholding of radical treatment other than recumbency until the diagnosis can be confirmed. They seem to suggest that faulty posture and intestinal derangements may in certain cases have some relation to coxitis.

372 Marlborough Strect.

\section{ABSTRACT OF DISCUSSYON}

Dr. Joel E. Goldthinait, Boston: We must recognize that the physiologic processes of the body on which the nutrition of bones and joints depends should be brought to the highest possible standard, so that the individual may have the greatest possibility of repair. The work of Sir Arbuthnot Lane is suggestive in this connection. When a man of his experience short-circuits the bowel of all children with tubetculosis of the joints caused by general toxemia, and obtains such good results it should make us think. We may not be willing to short-circuit a bowel, when the bowel is already too short in these children, nevertheless, we may make it functionate better, and so stop the toxemia, as Dr. Osgood has suggested. If we examine children, not only with reference to local joint inflammation, but also with reference t. :he er-tire body, we shall do well. If we think first of the child as a machine, and consider the disposition of his organs through his standing so badly out of poise, we will see that the normal physiologic action cannot take place. We must huild up the resistance by improving the physiologic action, intestinal and otherwise, as well as protect the joints.

Dr. Compton Riely, Baltimore, Md.: Dr. Osgood's paper brings up another question in the diagnosis of tuberculosis, especially tuberculosis of the hip. It shows, I think, that we should be more careful in making our diagnoses of hipdisease. The more of these cases I see, the more doubtful I am of their absolute diagnosis as cases of tuberculosis. We have been taught that if children had pain in the hip, limitation of motion, night cries, etc., they had tuberculosis of the hip; and we used to treat these cases as such, but we must be careful to make a more definite diagnosis in the future. In order to do that we must take time to go through every. test and examination that we can think of. If we did this we should find fewer absolute cases of tuberculosis than some of us think.

Dr. Charles A. Parker. Chicago: There is at least one method by which a diagnosis in some of these cases can be reached. This is by learning the causative factor, according to the methot of Dr. E. C. Rosenow of Chicago. In osteoarthritis of the knee he took out the inguinal glands which enabled him to make the diagnosis in twenty-three cases; he found the infectious agent in the blood and teeth, and was able to reproduce the disease in animals. His method of diagnosis will probably come rapidly into vogue. The lymphatic glands are taken from the region drained.

Dr. Frederick Hodgson. Atlanta. Ga.: I confirm Dr. Osgood's observations on these conditions of the hip. Dr. Michacl Hoke of Atlanta read a paper some time ago on toxic arthritis of the hip; and since then we have been careful in making these diagnoses at the first visit. We put the patients to bed with the best of hygienic surroundings, use colon lavage and get them into the best possible condition. We find that in this way many cases will clear up.

Dr. W. G. Stern, Cleveland: Reasoning backward from Dr. Osgood's observations, we come to consider the fact that the differential diagnosis of these cases from gentuine cases of tuberculous coxitis can be best made by the tuberculin reaction. At the meeting of the American Orthopedic Association in Cincinnati, I reported on a combination of the von Pirquet and the Calmette tests as a reliable guide in making the diagnosis of tuberculous coxitis. I reported cases in which the von Pirquet and Calmette tests were negative in the presence of suspicious joint-pain. One was the case of $\mathrm{my}$ own son, who had had, within six months, four attacks of night cries with fixation of the limb in adduction and flexion, muscle spasm and slight limp. Rocntgenoscopy and the tuberculin tests were negative and we found that the condition was due to a toxic absorption from the bowel from the ingestion of veal. On cleaning out the bowel and keeping the boy at rest we overcame this condition. Then we gave him some roast veal and brought on another attack. Some persons have an idiosyncrasy to certain kinds of food. In this case the idiosyncrasy was to veal. Since then I have looked for other cases and found one, a year ago, in a girl who presented very much the same posture that Dr. Osgood has shown in his cases. By methods similar to those that he has pointed out a cure has been effected.

Dr. Roland Meisenibach, Buffalo: What applies to children also applies to adults. I had one case in a woman 27 years of age who complained of coxalgia. Hyperextension of the hip-joint was limited on the right side and she also had pain over the region of the appendix, although the surgeon could not find an actual appendicitis. Bismuth oxychlorid was given her in small doses over a period of a week. The symptoms disappeared entirely and hyperextension was regained.

Dr. R. B. OsGoon, Boston: Dr. Parker's suggestion is valuable, but it must be remembered that various men have recently shown that these bacteria stay in the blood a very short time indeed. In these attacks, therefore, it would be difficult to catch them in the blood at the time and confirm 
the diagnosis by means of the glands; and I believe that frequently glands that are causing no trouble will show, by culture, some bacterial growth. Hence, while that suggestion is helpful in cases that we believe represent toxemia rather than definite bacterial infection of the joint, yet I do not think it is of a great deal of use in cases of definite bacterial infection. I was much struck with Dr. Stern's valuable observation of an arthritis of the hip caused by the ingestion of veal.

\section{THE SYNDROME OF ADRENAL INSUFFI- CIENCY *}

TOM A. WILLIAMS, M.B., C.M. (EDIx.)

Neurologist to Epiphany Dispensary and Freedmen's Hospital WASHINGTON, D. C.

To the neurologist many cases are referred with the diagnosis of neurasthenia. Many of these are psychologic, being in reality a fixed idea of incapacity derived from the suggestions of medical men or friends, or, perhaps, because of some internal mental conflict which makes the motives for invalidism paramount over those for normal active life. Such patients often actually do become weak, either from mere inaction, or from the malassimilation induced thereby and the worries they permit themselves; this is a familiar picture in a traumatic neurosis, ${ }^{1}$ so-called. But among those labeled neurasthenics, there is a certain proportion of patients in whom hysteria is not the factor at all; I do not here refer to psychasthenic patients, in whom anxiety and other features of psychic genesis dominate the picture; nor do I include the formes friustes of such psychoses as cyclothymia (manic depressive insanity), hebephrenia, etc. I refer to cases in which definite somatic disturbances are ascertainable, and in which any psychologic symptoms prescnt are dependent on these. Among such cases of "nenrasthenia" are persons with latent abdominal or pelvic inflammations, petit Brightisme, arterial hypertension and the metabolic disorders which precede it, early stages of cerebrospinal lues, especially that called paresis, and quite often perversion of function of the glands, more especially the thyroid.

Among such cases, I have encountered several in which none of the foregoing conditions were present, but in which the patients were suffering from a profound depression of the neuromuscular functions, quite different from that which is induced mentally or from disturbances of the brain. These are characterized by great asthenia, with lack of concentration, by low blood-pressure, sometimes by psychologic peculiarities, and sometimes by changes in pigmentation. I select a few as paradigms:

Cases may be divided into three classes:

1. Those in which there was improvement or recovery.

2. Those in which there was not.

3. Those which ended fatally.

\section{CASES WITH IMPROVEMENT OR RECOVERY}

CASE 1.-History.-A man holding a high position under the federal government was brought to me by his friend, Dr. Gerrish of Portland, Maine, in 1911. He complained that he

* Read before the Section on Practice of Medicine at the Sixty-Fitrir Annual Session of the American Medical Association, Atlantic City, A. J., June, 1914 .

Because of lack of space this article is abbreviated in THE Journal.

1. Williams, Tom A.: Idea and Emotion in Traumatic Neurosis, Jour. Abnormal Psychology, 1910; Psychic Effects of Accidents, Tr. Couthern Soc. Ry. Surg., and Monthly Cyclopedia, 1912, v, 47; v, 650, $\div 22$. was totally unable to bring himself to deal with the responsibilities of managing the situations with which he had to deal. besides which he was greatly depressed mentally and believed that his usefulness was ended. He "can do work if it does not demand responsibility or the handling of men," for he "finds that his judgment one day takes a certain course oily to be deflected the next day, even though the facts may be the same." He can make up his mind neither to accept a yachting invitation to Europe he has received, nor to take a professorship he has been offered for next year. He was pale, languid, had flabby muscles and subcutaneous tissues. He had typhoid at 18 , and pleurisy at 20 . Two years before he had a rise of temperature and a rapid and irregular heart, the cause of which was unknown. He has always taken his work responsibilities very hard. He is a bachelor of a somewhat retiring disposition, which his need for long inspection trips in the West has accentuated.

Physical Examination.-This was negative, except that there was a very slight tremor, the heart sounds were feeble, the systolic pressure was 100 and diastolic pressure 70 .

Treatinent and Result.-The psychologic situations were entered into with the patient very thoroughly, and it was explained that a simple physical depression from want of adrenal juice prevented the brain from accomplishing the processes necessary for the complex psychologic adaptations which had always caused stress on account of his overconscientious way of regarding his relations with others. He was told that worrying would only aggravate the distress, and that. his mental incapacity did not arise from what he feared, impending dementia; it would disappear on rectification of his physical state, the nature of which was explained to him. His diet was regulated and he was ordered much rest along with active exercises in short periods. He was given dried adrenal gland tablets, 2 grains thrice daily. The following week there was an improvement, the systolic bloodpressure was 98 , diastolic 70 ; ten days later the pressures had risen to 114 and 80 , respectively, he felt better and looked fresher. The following week after sleeping much, he folt better, but still had no spring; the blood-pressures were 112 and 70 , respectively. He was staying witl friends, worrying less and clearing up his work preparatory to a vacation in the Maine woods. Just before leaving, two weeks later, his pressures were 113 and 80 , respectively; he was now more hopefui and more comfortable in mind; the pulse rate remained 70 throughout.

In the fall of 1912 he returned very much better, the close of adrenal substance having been reduced until finally he: went without it; the blood-pressure runs around 118 and 80. and although he has never completely regained his spring and ambition, he is much better, "feels fit," and has undertaken all the work for the government which he had planned.

CASE 2.-A mechanic, aged 57, was referred in Feloruary, 1912, by Dr. Jackson; he had done no work after an attack of malaria the preceding September, because he had heen very weak and dizzy and had a throbbing in the abdomen. Examination showed a tremor a little like that seen in paralysis agitans, but occurring only on spreading the hands, and a slight tremor of the hands and face; there was slight: asthenia, and a hint of von Graefe's sign, especially when he was made to look down rapidly. The blood-pressure was systolic, 108; diastolic, 78; no other abnormalities were found. He was returned to his physician with a reserved prognosis, and a recommendation for massage, a proper standard dietary, and adrenal substance. These measures improved him so much that he returned to work and has been well ever since. His physician says that he has never seen such a transformation.

CASE 3.-History.-A professo. of economics, aged 44, was referred to me by Dr. Newell in March, 1913, because of headaches for six years, especially when tired after using the eyes. Twenty-one oculists had failed to relieve him in this country and in Europe. An internist had found nothing the matter with him. He complains also that at times his whole body is sore, especially the neck, and he often awakes with a pain over the sacrum, dull and heavy, radiating and intermittent, which may be removed for a time by a bath; there 